The Labore Journal of Economics

$10: 1$ (Summer 2005) pp. 1-14

\title{
The Dynamics of Rural Poverty in Pakistan: A Time Series Analysis
}

\author{
Abdul Saboor and Zakir Hussain"
}

\section{Abstract}

At the start of the 21st century, almost one-fifth of humanity-1.2 billion people-live on less than a dollar a day. Pakistan is confronted by a multifaceted dilemma. The major issues facing the country are poverty and income disparity, particularly among the rural segments of the society. And evidence indicates that both have worsened. The impact of poverty is particularly acute on the most vulnerable sections of the society. In the year 1990-91, 39.42 percent of the total 31.81 percent of the population below the poverty line were termed as absolute poor including 34 percent chronically and 61 percent extremely poor. During the last decade or so, nearly 2 million people are added to the clusters of extremely poor, 5 million to chronically poor, 7 million to transient poor. Thus bringing nearly 59.11 percent of the poor population out of poverty is to a certain extent easier than bringing the remaining 40.89 percent out of the poverty trap. Pakistan has witnessed a decline in the growth rate from 6.1 per cent during the 1980s to 4.2 percent during the 1990s. However, the Poverty Equivalent Growth Rate (PEGR) analysis reported in this paper indicates that the pro-poor growth scenario is improving in rural Pakistan. If growth remains pro-poor in the subsequent years as it was in the year 2000-01, there is a likelihood that the growth will trickle down to the poor more than the non-poor. Punjab province also showed an improving trend in terms of pro-poor growth in the analysis. In order to improve PEGR, the poverty alleviation policy must be accompanied by rational income distribution.

\section{Introduction}

The existence of pervasive poverty in the midst of global opulence is a daunting challenge confronting the world today. At the start of the 21st

\footnotetext{
* The authors respectively are lecturer Department of Agricultural Economics and Dean, Faculty of Agricultural Economics and Rural Sociology, University of Agriculture, Faisalabad.
} 
century, almost one-fifth of humanity-1.2 billion people- live on less than a dollar a day. Rural poverty accounts for nearly 63 percent of poverty worldwide (World Bank, 2004). Out of total 1.2 billion poor more then 900 million live in rural areas around the globe and the count for Asia and the Pacific is 90 percent out of a total of 800 million poor (IFAD, 2002). It is due to this global threat of poverty that at the UN Millennium Summit in September 2000, the International Development Community of 149 countries, adopted the Millennium Development Goals (MDG), thereby agreeing to halve acute poverty from the 1990 level (less than $\$ 1$ a day) by 2015 as the first and most important goal.

Pakistan is faced with a multifaceted dilemma. The major issues are poverty and income disparity particularly among the rural segments of the society. Pakistan has witnessed over the last three decades periods of high economic growth, as in the 1960s, accompanied with increasing poverty levels, periods of low economic growth, as in the 1970s accompanied by reduction in poverty levels, spells of high economic growth leading to decline in poverty as in the 1980s and periods of low economic growth as in the 1990s accompanied by increasing poverty levels. The growth rate declined from 6.1 per cent during the 1980 s to 4.2 percent during the 1990s (Amjad, 2004). The impact of the crisis of poverty is particularly acute on the most vulnerable sections of the society: women and children (UNDP, 2003).

Thus the study in hand is undertaken to determine a threshold level of poverty using rigorous economic tools coupled with trend analysis of rural poverty in terms of chronic and transient poor in the country. It further aims at developing a poverty equivalent growth rate which reflects the propoor growth scenarios in the rural areas.

\section{Review of Previous Studies}

By the very standard of $\$ 1$ a day, as reported in World Development Indicators for 2001, 31 percent of Pakistan's population fell under the poverty line in 1996. The extent of poverty in rural areas increased from 37.0 percent in 1998-99 to 44.6 percent in 2000-01 (Kemal, 2003). Anwar and Qureshi (2002) concluded that the use of consistent time series estimates of the poverty line shows that the head count measure of poverty has increased from 17.2 percent in 1990-91 to 30.4 percent in 1998-99 and 35.6 percent in 2001. World Bank (2002) estimated that there was a decline in the poverty rate by 2 percentage points during the $1990 \mathrm{~s}$ while the Asian Development Bank (2002) claimed that poverty had increased over this period. 
There is increasing evidence that the prevalence of transient poverty is significantly greater that that of chronic poverty in many parts of the developing world. Jalan and Ravallion (2000) found that 49.39 percent of the squared poverty gap in China is transient, while Gaiha and Deolalikar (1993) noted that over nine years, chronic poverty accounted for only one fifth of the total poverty in the ICRISAT VLS panel of rural south India. Baulch and McCulloch (1999) using a five round panel data set for Pakistan find that only 3 percent of the households were poor in all five years and half were poor in at least one period.

\subsection{Dilemma of Economic Growth: Necessary Condition}

The recent analyses of large international and interregional data sets show that the structure of growth is a major factor in explaining the bulk of poverty reduction. The structure of growth does indeed matter very much. The other factor of importance is the initial condition of income distribution. The skewed distribution of income and land not only slows down growth but does not help in reducing poverty. The substantial empirical evidence suggests that a high inequality in income is not conducive to either economic growth or poverty reduction.

Pakistan requires a high growth rate in agriculture, well above the population growth rate, in order to reduce poverty. In order to obtain two percent growth rate per capita, Pakistan requires a 4.6 percent rate of agricultural growth. India, with 1.3 percent rate of population growth in the same period, only requires a 3.3 percent rate of agricultural growth to get 2 percent per capita. In agriculture, the difference between 3.3 percent and 4.6 percent is significant. It is the rate of growth of agricultural output per capita that gives a boost to demand growth for the rural non-farm sector that subsequently checks the momentum of poverty (Me1lor, 2001).

\subsection{Distributive Pattern of Growth: Sufficient Condition}

Ravallion and Chen (2002) defined growth as pro-poor if it reduces poverty. Dollar and Kraay (2001) opined that positive economic growth benefits the poor to the same extent that it benefits the whole economy. Similarly Knowles (2001) finds a significant negative effect of inequality on growth. Foster and Szekely (2000) showed that growth elasticity of the general means can vary from 1.08 to extremely low. They concluded that the positive value of elasticity indicates that growth is good for the poor. The Foster-Szekely approach provides an important bridge to the design of welfare measures sensitive to and incorporating poverty and inequality- a 
high priority in the research agenda in development economics. It is, therefore, argued that to achieve rapid reduction in poverty, the Poverty Equivalent Growth Rate (PEGR) is to be maximized instead of normal growth rate alone (Kakwani and Son, 2004).

\section{Materials and Methods}

The study in hand is a secondary data based study. It covers the period from 1990-91 to 2000-2001 using time series data obtained from the various issues of Household Income and Expenditure Survey. The HIES is conducted in four rounds by the Federal Bureau of Statistics, Statistics Division, Government of Pakistan, on an irregular basis covering both rural and urban areas in the four provinces of Pakistan. Despite some limitations, HIES data sets are the best available source to analyze the gender and demographic dimensions of poverty in Pakistan. There are two major methodological considerations to achieve the objectives.

\subsection{Pockets of Poor Population: Methods of Fixing Poverty Band}

The condition called poverty is not confined to the population below the poverty line, but goes beyond and includes the people residing above the poverty line with high probability of falling below it. Following the classification of McCulloch and Baulch (1999), the population is distributed into six groups by income quartiles around the poverty line and analyzes the poverty dynamics by comparing salient characteristics of these quartile bands for the period under consideration.

\subsection{The Absolute Poor Household Band}

If the per capita per month income of the household is less than 75 percent of the poverty line, it is declared as an absolute poor household which is further subdivided into extremely and chronically poor bands:

$\begin{array}{ll}\text { i) Extremely Poor Band: } & \mathrm{Y}<0.5 \mathrm{Z} \\ \text { ii) Chronically Poor Band: } & \mathrm{Y}>0.5 \mathrm{Z} \text { and } \mathrm{Y}<0.75 \mathrm{Z}\end{array}$

Where:

$\mathrm{Y}=$ household per capita per month income.

$\mathrm{Z}=$ Poverty line. 


\subsection{The Transitorily Poor Household Band}

If the per capita per month income of the household is less than 125 percent of the poverty line and more than or equal to 75 percent of the poverty line, it is termed as transitorily poor household which is further subdivided into Transitory Poor and Transitory Vulnerable Bands.
i) Transitory Poor Band:
$\mathrm{Y}>0.75 \mathrm{Z}$ and $\mathrm{Y}<\mathrm{Z}$
ii) Vulnerable Poor Band:
$\mathrm{Y}>\mathrm{Z}$ and $\mathrm{Y}<1.25 \mathrm{Z}$

\subsection{The Non-Poor Household Band}

If the per capita per month income of the household is more than or equal to 125 percent of the poverty line, it is categorized as a Non-poor Household which is further subdivided into Transitory Non-Poor and NonPoor Bands.
i) Transitory Non-Poor Band:
$\mathrm{Y}>1.25 \mathrm{Z}$ and $\mathrm{Y}<2 \mathrm{Z}$
ii) Non-Poor Band:
$\mathrm{Y}>2 \mathrm{Z}$

\subsection{Head-Count Index of Poverty}

It is the proportion of population whose income(y) is less than the poverty line $\mathrm{Z}$. It is obtained by counting the number of persons (and in some studies households) whose expenditures are below $\mathrm{Z}$ and denoting these as a proportion of the total population. Hence:

$$
\begin{aligned}
& \mathrm{H}=\mathrm{q} / \mathrm{n} \\
& \mathrm{H}=\text { Head-count index } \\
& \mathrm{q}=\text { number of poor } \\
& \mathrm{n}=\text { size of the population }
\end{aligned}
$$

\subsection{Poverty Equivalent Growth Rate (PEGR)}

According to Ravallion and Chen (2004), growth is defined as pro-poor if it reduces poverty. This definition is similar to the trickle down theory. Trickle down development indeed reduces poverty but the rate of poverty reduction may be much slower. Pro-poor growth calls for enhancing growth and goes beyond the idea of trickle down. On this account, pro-poor growth 
may be preferably classified as the growth that delivers proportionally (or absolutely) greater benefits to the poor than to the non-poor. Pro-poor growth can be defined in relative and/or absolute terms.

Suppose income $\mathrm{X}$ of an individual is a random variable with distribution function given by $F(x)$. Let $z$ denote the poverty line, which measures the society's minimum standard of living. A person suffers absolute deprivation if his income is less than $z$. If his income is greater than or equal to $z$, we say that he does not suffer any deprivation. $H=F(z)$ is the proportion of individuals who suffer absolute deprivation because their income is below the society's minimum standard of living. HCR (Head Count Ratio) measures the incidence of poverty. Being a crude measure of poverty it assumes that every one whose income is below the poverty line suffers the same degree of deprivation. To take account of the intensity of deprivation, we define the degree of absolute deprivation suffered by an individual with income $\mathrm{x}$ as

$$
\begin{aligned}
\operatorname{Dep}(\mathrm{x}) & =\mathrm{P}(\mathrm{z}, \mathrm{x}) & & \text { if } \mathrm{x}<\mathrm{z} \\
& =0 & & \text { if } \mathrm{x} \geq \mathrm{z}
\end{aligned}
$$

Where $\mathrm{P}(\mathrm{z}, \mathrm{x})$ is a homogenous function of degree zero in $\mathrm{z}$ and $\mathrm{x}$.

$$
\begin{gathered}
\frac{\mathrm{P}(\mathrm{z}, \mathrm{x})}{\mathrm{x}}<0 \\
\frac{{ }^{2} \mathrm{P}(\mathrm{z}, \mathrm{x})}{\mathrm{x}^{2}}>0
\end{gathered}
$$

which implies that deprivation decreases monotonically with income at an increasing rate. The degree of poverty in the society may be measured by the average deprivation suffered by the society, which is given by

$$
\theta=0{ }^{\mathrm{Z}} \mathrm{P}(\mathrm{z}, \mathrm{x}) \mathrm{f}(\mathrm{x}) \mathrm{dx}
$$

where $f(x)$ is the probability density function of $x$. This is a general class of additive poverty measures.

Poverty reduction largely depends on two factors. The first factor is the magnitude of economic growth rate: the greater the growth rate, the greater the reduction of poverty. Secondly, growth is generally accompanied by changes in inequality: an increase in inequality reduces the impact of growth on poverty reduction. 
To measure these two impacts, we differentiate equation (2) to obtain

$$
d \theta / \theta=1 / \theta_{0}^{Z} \quad P / x d(x) f(x) d x
$$

which follows from the assumption that $\mathrm{P}(\mathrm{z}, \mathrm{x})=0$ : if an individual's income is equal to the poverty line, then he or she does not suffer any deprivation. Suppose $\mathbf{x}(\mathrm{p})$ is the income level of population at the pth percentile. Eq (2) can be written as

$$
d \operatorname{Ln} \theta=1 / \theta_{0} \quad h \quad P / x x(p) g(p) d p
$$

Where $g(p)=d \operatorname{Ln}(x(p))$ is the growth rate of income of people on pth percentile.

Suppose $\mathrm{L}(\mathrm{p})$ is the Lorenz function, which measures the share of total income enjoyed by the bottom p proportion of population when the individuals in the population are arranged in the ascending order of their income.

Following Kakwani (1980), we can write

$$
X(p)=\mu L^{\prime}(p)
$$

Where $\mu$ is the mean income of the society and $L(p)$ is the first derivative of the Lorenz function. Taking logarithm of (5) and differentiating it, we obtain

$$
\mathrm{dLn}(\mathrm{x}(\mathrm{p}))=\mathrm{d} \operatorname{Ln}(\mu)+\mathrm{d} \operatorname{Ln}\left(\mathrm{L}^{\prime}(\mathrm{p})\right)
$$

which immediately gives

$$
\mathrm{g}(\mathrm{p}) \quad=\quad \gamma+\mathrm{dLn}\left(\mathrm{L}^{\prime}(\mathrm{p})\right)
$$

where: $\gamma=\mathrm{d} \operatorname{Ln}(\mu)$ is the growth rate of the mean income. Next, substituting (6) into (4) gives

$$
\mathrm{d} \operatorname{Ln} \theta=\gamma \eta+\mathrm{I} / \theta_{0}{ }^{\mathrm{h}} \mathrm{P} / \mathrm{x} \mathrm{x}(\mathrm{p}) \mathrm{dLn}\left(\mathrm{L}^{\prime}(\mathrm{p})\right) \mathrm{dp}
$$

where:

$$
\eta=\mathrm{I} / \theta_{0}{ }^{\mathrm{h}} \mathrm{P} / \mathrm{x} \mathrm{x}^{\mathrm{x}}(\mathrm{p}) \mathrm{dp}
$$

is the growth elasticity of poverty derived by Kakwani (1993), which is the percentage change in poverty when there is a 1 percent growth in mean income of the society, provided the growth process does not change 
inequality (when every one in the society receives the same proportional benefits of growth). This elasticity is always negative. Dividing (9) by y gives

$$
\delta=\eta+\zeta
$$

where $\delta=\mathrm{d} \operatorname{Ln}(\theta) / \mathrm{y}$ is the total poverty elasticity and

$$
\zeta=1 / \theta \gamma_{0}{ }^{\mathrm{h}} \mathrm{P} / \mathrm{xx}^{\mathrm{x}}(\mathrm{p}) \mathrm{dLn}\left(\mathrm{L}^{\prime}(\mathrm{p})\right) \mathrm{dp}
$$

measures the inequality effect of poverty reduction. It tells us how poverty changes due to changes in inequality during the growth process.

The growth is pro-poor (anti-poor) if the change in inequality that accompanies growth reduces (increases) the total poverty. Thus the growth is pro-poor (anti-poor) if the total elasticity of poverty is greater (less) than the growth elasticity of poverty.

The Poverty Equivalent Growth Rate (PEGR) is the growth rate $\gamma^{*}$ that will result in the same level of poverty reduction as the present growth rate $y$ if the growth process had not been accompanied by any change in inequality (when every one in the society had received the same proportional benefits of growth). The actual proportional rate of poverty reduction is given by $\delta y$, where $\delta$ is the total poverty elasticity. If growth were distribution neutral (when inequality had not changed), then the growth rate $\gamma^{*}$ would achieve a proportional reduction in poverty equal to $\eta \gamma^{*}$, which should be equal to $\delta \gamma$. Thus, the PEGR denoted by $\gamma^{*}$ will be given by

$$
\gamma^{*}=(\delta / \eta) f \gamma=\varnothing \gamma
$$

where $\varnothing=\delta / \eta$ is the pro-poor index, which was developed by Kakwani and Pemia (2000). This equation implies that growth is pro-poor (anti-poor) if $\gamma^{*}$ is greater (less) than $\mathrm{y}$. If $\gamma^{*}$ lies between $o$ and $\gamma$, the growth is accompanied by an increasing inequality but poverty still reduces. This situation may be characterized as a trickle down process when the poor receive proportionately less benefits of growth than the non-poor.

Thus, PEGR determines the equitable growth rate. Furthermore, the proportional reduction in poverty is an increasing function of $\gamma^{*}$ : the larger is $\gamma^{*}$, the greater is the proportional reduction in poverty. Thus, maximizing $\gamma^{*}$ is equivalent to maximizing the total proportional reduction in poverty. This suggests that the performance of a country should be judged on the basis of the poverty equivalent growth rate and not by the ordinary growth rate alone. 


\section{Empirical Estimates}

\subsection{Pockets of Poor Population: Poverty Bands}

It is important to distinguish that even within "the poor" all poor are not the same: some are poor occasionally while others are often poor; and for each category of the poor, their distance from the poverty line is not similar. Some of them are only marginally poor while others are severely poor, and often the former outnumber the latter, in other words, it is imperative to distinguish which component of poverty is chronic and which is transitory.

Thus, the poverty lines alone are not adequately helpful in exploring the dynamics of poverty in the country. The "dynamics" mean the inter quartile based movement of the population over the time period from 199091 to 2000-01. The data in Table 1 illustrates that 39 percent of the total 32 percent of the population below the poverty line was found as absolute poor with chronically and extremely poor in the proportion of 34 percent and 61 percent respectively in the year 1990-91. The extremely poor, chronically poor and transient poor constitute 1.72 percent, 10.82 percent and 19.27 percent of the overall population below the poverty line in rural Pakistan.

The transitorily poor constitute 32 percent; a major proportion (25 million) of the overall population in the rural areas. There is almost continuous increase in the proportion of absolute poor and transitorily poor segments of the society from 1990-91 to 2000-01. During the entire time series, 2 million people added to the clusters of extremely poor, 5 million to chronically poor, 7 million to transient poor and 7 million to the vulnerable poor. On the other hand, there is a consistent decrease in the proportion of non-poor, both transient non-poor and non-poor. In 1990-91, there were 17 million rural segments considered as non-poor while the number for this class reduced to 13 million in 2000-01; thereby this reflects a 3.21 percent decrease in non-poor in the rural areas over the whole decade.

Bane and Ellwood (1986) found that the majority of poor persons at any time are in the midst of a rather long spell of poverty. It is interesting to note that clusters of population very close to the poverty lines have significantly increased from 31.53 percent to 40.88 percent-which reflects a proportionate increase of 29.65 percent. This high proportion of the population close to the poverty line calls for policy attention. There is very little effort on the part of the government institutions to check the vulnerability phenomenon on the one hand and pulling the transiently poor out of the poverty trap on the other. Thus taking 59.11 percent of the poor population out of poverty is rather easier than bringing the remaining 40.89 
percent out of the poverty trap. Moreover, "halving poverty", as per one of the Millennium Goals (MDGs), seems an achievable target through target oriented economic policies.

There is a shift in population from the upper poverty bands into the lower ones; showing a decline in their welfare level and hence influx into poverty. The situation becomes alarming when the non-poor of one period have become poor in the next period. This makes poverty alleviation a two dimensional task; making sure that those under the poverty line are brought up and those above it maintain their status-quo. It is extremely important for any poverty reduction strategy.

Table-1: The Dynamics of Rural Poverty in Pakistan (Time Series Analysis)

\begin{tabular}{lcccccc}
\hline Poverty Dynamics & $\mathbf{1 9 9 0 - 9 1}$ & $\mathbf{1 9 9 2 - 9 3}$ & $\mathbf{1 9 9 3 - 9 4}$ & $\mathbf{1 9 9 6 - 9 7}$ & $\mathbf{1 9 9 8 - 9 9}$ & $\mathbf{2 0 0 0 - 0 1}$ \\
\hline Extremely Poor & 1.72 & 1.95 & 2.01 & 2.14 & 2.55 & 2.70 \\
& $(1.3)$ & $(1.6)$ & $(1.6)$ & $(1.9)$ & $(2.3)$ & $(2.5)$ \\
Chronically Poor & 10.82 & 11.25 & 11.54 & 12.48 & 12.76 & 13.25 \\
& $(8.4)$ & $(9.1)$ & $(9.5)$ & $(10.9)$ & $(11.605)$ & $(12.4)$ \\
Transient Poor & 19.27 & 19.98 & 20.65 & 21.98 & 22.59 & 23.06 \\
& $(15$ & $(16.2)$ & $(17.0)$ & $(19.3)$ & $(20.5)$ & $(216.4)$ \\
Transient Vulnerable & 12.26 & 13.72 & 14.08 & 14.00 & 16.08 & 17.82 \\
& $(9.5)$ & $(11.1)$ & $(11.6$ & $(12.3)$ & $(14.6)$ & $(16.7)$ \\
Transient Non-Poor & 34.20 & 33.10 & 32.02 & 31.00 & 30.35 & 29.12 \\
& $(26.6)$ & $(26.8)$ & $(26.5)$ & $(27.1)$ & $(27.5)$ & $(27.3)$ \\
Non-Poor & 21.73 & 20.00 & 19.70 & 18.40 & 15.67 & 14.05 \\
& $(17)$ & $(16)$ & $(16)$ & $(12)$ & $(14)$ & $(13.2)$ \\
\hline
\end{tabular}

Figures in parenthesis indicate rural population in "million"

\subsection{Poverty Equivalent Growth Rate}

This study further examines to what extent the rural poor benefit from agricultural economic growth. The index of pro-poor growth, known as Poverty Equivalent Growth Rate (PEGR), takes into account both the magnitude of agricultural growth and its benefits to the rural poor. The PEGR demonstrates that proportional reduction in rural poverty is a monotonically increasing function: the larger the PEGR, the greater the proportional reduction in rural poverty. The PEGR that satisfies the monotonic relation with poverty reduction, therefore, is not only a necessary but also a sufficient condition for poverty reduction in the rural areas of Pakistan. 
In this study, PEGR scenarios are reported in Table-2. The short term PEGR revealed that agricultural growth is anti-poor in Pakistan and in all provinces from 1990-91 to 1992-93 and in the subsequent years (from 1992-93 to 1998-99), showed pro-poor growth in rural Pakistan. The Punjab province also follows the same pattern of pro-poor growth in the agricultural sector. In Sindh and NWFP, there is only one short term period (from 1996-97 to 1998-99) when the growth was pro-poor because the values of PEGR rates are greater than that of the agricultural growth rates.

However, the short run PEGR results are not sufficient to show unambiguous decision results whether growth has been pro-poor or antipoor. Pro-poor growth is more a long term phenomenon rather than short run because of trickle down lag to the poor particularly in rural areas. Moreover, inconsistency in the HIES data creates empirical difficulties, thus short term PEGRs do not lead to conclusive policy initiatives. Among all provinces, Balochistan is the only province where agricultural growth showed a pro-poor scenario from 1990 to 2001 though anti- poor growth was observed in some short term periods. NWFP is the worst case in the series where policies remained anti-poor in most of the years.

In this way, the short run PEGR analysis revealed that the pro-poor growth scenario is improving in rural Pakistan. If the growth remains propoor in the subsequent years as reflected in the year 2000-01, there is a likelihood that growth trickles down to the poor more than the non-poor. Punjab province also showed an improving trend in terms of pro-poor growth in the analysis. However, the situation is alarming in other provinces because of anti-poor growth.

Table-2: The Actual and Poverty Equivalent Growth Rates (Time Series Analysis)

\begin{tabular}{lcccccc}
\hline Areas & $\begin{array}{c}\mathbf{1 9 9 0 - 9 1} \\
\text { to } \\
\mathbf{1 9 9 2 - 9 3}\end{array}$ & $\begin{array}{c}\mathbf{1 9 9 2 - 9 3} \\
\text { to } \\
\mathbf{1 9 9 3 - 9 4}\end{array}$ & $\begin{array}{c}\mathbf{1 9 9 2 - 9 3} \\
\text { to } \\
\mathbf{1 9 9 6 - 9 7}\end{array}$ & $\begin{array}{c}\mathbf{1 9 9 6 - 9 7} \\
\text { to } \\
\mathbf{1 9 9 8 - 9 9}\end{array}$ & $\begin{array}{c}\mathbf{1 9 9 8 - 9 9} \\
\text { to } \\
\mathbf{2 0 0 0 - 0 1}\end{array}$ & $\begin{array}{c}\mathbf{1 9 9 0 - 9 1} \\
\text { to } \\
\mathbf{2 0 0 0 - 0 1}\end{array}$ \\
\hline Pakistan & 1.48 & 16.13 & 89.60 & -1.50 & 8.47 & -86.03 \\
& $(3.07)$ & $(5.20)$ & $(6.13)$ & $(3.20)$ & $(3.40)$ & $(4.7)$ \\
Punjab & -5.19 & 0.79 & 9.66 & -0.39 & 6.45 & -92.00 \\
& $(7.33)$ & $(0.94)$ & $(9.8)$ & $(-0.45)$ & $(6.01)$ & $(7.8)$ \\
Sindh & -13.4 & -20.54 & -16.21 & 13.80 & -16.45 & -26.18 \\
& $(8.99)$ & $(6.48)$ & $(6.10)$ & $(8.47)$ & $(-2.51)$ & $(8.16)$ \\
NWFP & -8.14 & -16.87 & -48.9 & 11.44 & -32.52 & -107 \\
& $(6.70)$ & $(18.36)$ & $(4.5)$ & $(5.54)$ & $(1.92)$ & $(3.98)$ \\
Balochistan & 17.09 & -9.5 & 21.6 & 35.97 & -13.52 & 63.36 \\
& $(9.83)$ & $(5.62)$ & $(5.11)$ & $(11.17)$ & $(2.63)$ & $(2.16)$ \\
\hline
\end{tabular}

Figures in parenthesis indicate the growth rates in mean incomes. 


\section{Conclusions and Recommendations}

In conclusion, the short term PEGR revealed that agricultural growth is anti-poor in Pakistan (including Punjab Province) in the early 90s and in the subsequent years showed pro-poor growth. However, in Sindh and NWFP, growth was pro-poor in the mid 90s. In Pakistan, growth though positive for most of the periods, has been anti-poor and PEGR is negative. Bhagwati (1988) calls this "immiserizing" growth where more affluent farmers adopt new seeds and raise production that results in lower prices. The small farmers also benefit from economic growth but to a lesser extent than the large farmers.

The study further found that pro-poor growth is more a long term phenomenon rather than short run due to time lag in trickle down to the poor, particularly in rural areas. Among all provinces, Balochistan is the only province where, agricultural growth showed a pro-poor scenario from 1990 to 2001 though anti-poor growth was observed in some short term periods. NWFP is the worst case in the series where policies remained anti-poor in most of the years.

The poverty alleviation initiative should follow two dimensional approaches; making sure that those under the poverty line are brought up and those above it maintain their status-quo. The government should focus on poverty equivalent growth rate in agriculture rather than the actual growth rates. The trickle down philosophy is simply not working in highly populated pockets of the poor of Pakistan. In order to improve PEGR, the poverty alleviation policy must be in tandem with rational income distribution.

The dynamic analysis of rural poverty is an ignored area of research in Pakistan which, if thoroughly appraised, would certainly create comfortable room for the policy makers to frame different sets of target oriented policies for various segments of the society separately. One should be careful in setting the poverty threshold keeping in view poverty lines and poverty bands. Moreover, the same time series analysis needs to be undertaken at provincial and cropping zone levels. A comprehensive policy is extremely important for a sound poverty reduction strategy. Thus, checking vulnerability would offer a wide option for the policy makers to settle the issue of the severity of poverty in the future. Thus, the PEGR is more feasible than simple emphasis on a general growth rate in agriculture. 


\section{References}

Amjad, R. 2004, Solving Pakistan's Poverty Puzzle: Who should we believe? What should we do?, PSDE, $19^{\text {th }}$ Annual Conference, $13^{\text {th }}-15^{\text {th }}$ January, Islamabad.

Anwar, T. and S. K. Qureshi 2002, Trends in Absolute Poverty in Pakistan: 1990-91 and 2001, Pakistan Development Review, Winter 2002, Islamabad.

Asian Development Bank 2002, Poverty in Pakistan: Issues, Causes and Institutional Responses, Pakistan Resident Mission, Islamabad.

Bane, M. J. and D. Ellwood. 1986, 'Slipping in and out of Poverty: The Dynamics of Spel1s', Journal of Human Resources, Vo1.21, Vo1.1, $1-23$.

Bhagwati, J. N. 1988, Poverty and Public Policy, World Development Report $16(5)$, pp. 539-654.

Dollar, D. and Kraay, A. 2001, "Growth is Good for the Poor" Washington, D.C., World Bank, Policy Research Working Paper 2587:50.

Foster, J. and Szekely, M. 2000, "How good is growth?" Asian Development Review, 18, 2 pp. 59-73.

Gaiha R. and A. B. Deolalikar 1993, Persistent, expected and innate poverty: estimates for Rural South India, 1975-84, Cambridge Journal of Economics, 17(4): 409-421.

Government of Pakistan (Various Issues). Household Integrated Economic Surveys, Federal Bureau of Statistics, Statistics Division, Islamabad.

International Fund for Agricultural Development 2002, Enabling the Rural Poor to over come Poverty, Annual Report, IFAD, Rome, Italy.

Jalan, J. and M. Ravallion 2000, Is transient poverty different? Evidence for rural China, Journal of Development Studies, Vo1.36, No.6, pp. 82-99.

Kakwani, N. 2003, Issues in Setting Absolute Poverty Lines, Poverty and Social Development, Paper No. 3, Regional and Sustainable Development Department, Asian Development Bank. 
Kakwani, N. and H. H. Son 2004, Pro-Poor Growth: Concepts and Measurement, PSDE, $19^{\text {th }}$ Annual Conference, $13^{\text {th }}-15^{\text {th }}$ January, Islamabad.

Kakwani, N. and Pemia, E. 2000, What is Pro-poor Growth, Asian Development Review, Vo1. 16, No. 1,pp. 1-22.

Kakwani, N. 1980, Income Inequality and Poverty Review: Methods of Estimation and Policy Applications, Oxford University Press, New York.

Kema1, A. R. 2003, Structural Adjustment And Poverty In Pakistan, Mimeo Technical Paper Series No. 14, Pakistan Institute of Development Economics, Islamabad.

Knowles, S. 2001, "Inequality and economic growth: the empirical relationship reconsidered in the light of comparable data". Paper prepared for WIDER conference on 'Growth and Poverty', WIDER, Helsinki.

McCulloch, N. and Baulch, B. 1999, "Distinguishing the chronically from the Transitory Poor: Evidence from Rural Pakistan”, Paper presented at IDS-IFPRI Workshop on Economic Mobility and Poverty Dynamics, Institute of Development Studies, 7-8 April, 1999.

Mellor, John W. 2001, "Employment Multiplier from Agricultural Growth and Poverty Reduction”, The Pakistan Development Review, 40: 4 Part I (Winter 2001) pp. 371-400.

Ravallion, M. and Chen, S. 2002, "Measuring Pro-poor Growth", World Bank, Working Paper no.2666.

United Nation Development Programme: UNDP, 2003, National Human Development Report, Poverty. Growth and Governance, Oxford University Press, Karachi.

World Bank, 2002, Poverty in Pakistan: Vulnerabilities, Social Gaps and Rural Dynamics Washington D.C.

World Bank, 2004. www.worldbank.org. 